\title{
A mouthful - airway matters in intraoperative neuromonitoring in auditory brainstem implant surgery for the pediatric patient: a case series
}

\author{
Charis Khoo ${ }^{1,2^{*}}$ (D) A. H. NurHafiizhoh ${ }^{1}$, Angela Tan ${ }^{1,2}$, Tracy Tan ${ }^{1,2}$ and Hwan Ing Hee ${ }^{1,2}$
}

\begin{abstract}
Background: The Auditory brainstem implant (ABI) is a new surgical option for hearing impaired children. Intraoperative neurophysiology monitoring includes brainstem mapping of cranial nerve (CN) IX, X, XI, XII and their motor nuclei, and corticobulbar tract motor-evoked potential. These require laryngeal electrodes and intra-oral pins, posing a challenge to airway management especially in the pediatric airway, where specialized electromyogram (EMG) tracheal tubes are not available.

Challenges include determining the optimum position on the endotracheal tube (ETT) in which to place laryngeal electrode, and the increase in external diameter of ETT contributed by the wrapping the electrode around the shaft of ETT; this may necessitate downsizing of the tracheal tube. An appropriate size ETT minimizes displacement, which in turn can affect electrode contact with the vocal cords. Finally, a small thus crowded pediatric airway makes for difficult visualization during placement of intraoral neuromonitoring electrodes. The use of a videolaryngoscope helps determine optimum electrode placement.

Case presentation: We describe intraoperative neurophysiology monitoring and airway management for the first two ABI procedures in Singapore, conducted for children with congenitally absent cochlear nerves.

Conclusion: Neurophysiology cranial nerve IX, X, XII monitoring in the ABI procedure requires intraoral placement of electrodes. Care should be exercised during placement and removal. Vagus nerve monitoring in children requires attention to tube preparation, and consideration should be given to avoidance of airway topicalization.
\end{abstract}

Keywords: Child, Auditory brain stem implants, Intraoperative neurophysiological monitoring, Airway management, Evoked potentials, motor

\section{Background}

The auditory brainstem implant is a novel treatment for hearing impairment [1]. ABI has been used for children in Europe over a decade, while clinical trials for children with non Neurofibromatosis-2 conditions was approved in United states in 2013 [2].

This series describes challenges in airway management and intraoperative neurophysiology monitoring for the first two cases in Singapore. We hope that this description

\footnotetext{
*Correspondence: Charis.Khoo.EH@singhealth.com.sg

'Department of Paediatric Anaesthesia, KK Women's and Children's Hospital,

100 Bukit Timah Road, Singapore 229899, Singapore

2DUKES NUS Medical School, Singapore, Singapore
}

will facilitate selection and preparation of tracheal tubes. This will conserve resources, and importantly, minimize airway trauma.

\section{Case presentation}

Informed consent was obtained from parents of both patients.

\section{Case presentation 1}

A 7-year-old, $18 \mathrm{~kg}$, ASA-PS 1 boy, with congenital bilateral sensorineural deafness and failed right cochlear implant. He underwent a Magnetic Resonance Imaging (MRI) before transfer to operating theatre for $\mathrm{ABI}$ insertion. During the

(c) The Author(s). 2018 Open Access This article is distributed under the terms of the Creative Commons Attribution 4.0 International License (http://creativecommons.org/licenses/by/4.0/), which permits unrestricted use, distribution, and 
MRI, his airway was secured with a size $5.5 \mathrm{~mm}$ internal-diameter (I.D.) uncuffed ETT.

Planned intraoperative neurophysiology monitoring included brainstem auditory sensory evoked potentials, brainstem mapping of CN IX, X, XI, XII and their motor nuclei, and corticobulbar tract motor-evoked potential (MEP). Lead placement for CN IX, X, XI, XII was performed by the anesthesia team.

$\mathrm{CN} \mathrm{X}$ monitoring (Fig. 1a) was performed using a $32 \mathrm{~mm}$ by $29 \mathrm{~mm}$ laryngeal electrode (Inomed, Emmendingen, Germany). To identify optimal electrode placement on the tracheal tube, the patient was positioned as intended for surgery (right lateral), and the depth of ETT corresponding to the laryngeal inlet was identified using C-MAC Laryngoscope (KARL STORZ, Deutschland). This corresponded to $6 \mathrm{~cm}$ at vocal cords $(15 \mathrm{~cm}$ at lips). A new \#5.5 uncuffed ETT was then prepared with the laryngeal electrodes (Fig. 1a) and the child re-intubated, in keeping with the measurements. Using C-MAC, the pin electrode for CN IX was placed on the ipsilateral soft palate; electrodes for CN XII were placed on the anterior tongue. Rolled up gauzes were placed on either side of the tracheal tube (Fig. 1b) to stabilize the tracheal tube, and as a bite block.

Total intravenous anesthesia (TIVA) included propofol (Paedsfusor Target Control Infusion, target plasma concentration $3.5-5.0 \mathrm{mcg} / \mathrm{ml})$ [3], remifentanil $(0.08-$ $0.3 \mathrm{mcg} / \mathrm{kg} / \mathrm{min})$ and ketamine $(0.2-0.33 \mathrm{mcg} / \mathrm{kg} / \mathrm{min})$. Analgesia included intravenous paracetamol $15 \mathrm{mg} / \mathrm{kg}$, morphine $2.5 \mathrm{mg}$ and local anesthetic infiltration.

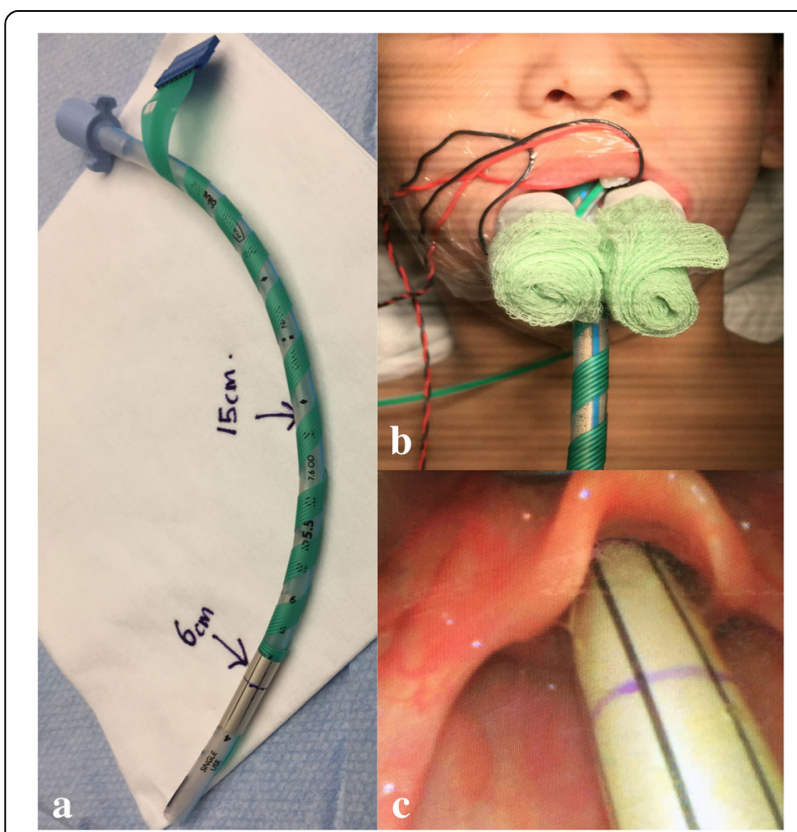

Fig. 1 a CN X electrode (sensor in silver). b Bilateral bite blocks minimise displacement. c Electrode displacement despite careful positioning (end procedure)
Anti-emetics (dexamethasone $0.2 \mathrm{mg} / \mathrm{kg}$, ondansetron $0.1 \mathrm{mg} / \mathrm{kg}$ ) were administered. Surgery was uneventful except for 3 episodes of transient bradycardia (40/min). Duration of procedure, including MRI was $9 \mathrm{~h}$.

\section{Case presentation 2}

A 6-year old girl, $18.9 \mathrm{~kg}$, ASA-PS 1, with congenitally bilaterally absent cochlear nerves scheduled for a right ABI implant.

A \#2.5 laryngeal mask was used during pre-operative MRI, and changed to a \#5.0 mm-internal-diameter microcuff tube for surgery.

The CN X electrode was wrapped above the ETT cuff at the level of the intubation depth marker $(4 \mathrm{~cm})$. The patient was then intubated using a C-MAC Pocket Monitor (KARL STORZ, Deutschland), the ETT secured at the depth of $4 \mathrm{~cm}$ at vocal cords, $12 \mathrm{~cm}$ at lips. Subsequently, the anesthetist placed intraoral electrodes, and the patient was then positioned for surgery.

Total intravenous anesthesia (TIVA) was conducted with propofol and remifentanil. Analgesia included paracetamol, morphine, and local anesthetic infiltration. Dual antiemetics, dexamethasone and ondansetron were administered. The procedure was uneventful.

In both, laryngoscopy at the end of procedure revealed cranially displaced tracheal tubes (Fig. 1c). Both patients experienced nausea with poor appetite for 2 days despite anti-emetics.

\section{Discussion and conclusions}

Intraoperative neuromuscular monitoring is necessary to prevent iatrogenic injury. Brainstem mapping of CN IX, $\mathrm{X}, \mathrm{XI}, \mathrm{XII}$ and their motor nuclei, and corticobulbar tract motor-evoked potentials help monitor function of cranial nerves, and integrity of ascending sensory tracts and descending motor pathways [4]. Brainstem auditory evoked responses confirm successful device implantation.

Lead placement for cranial nerves IX, X, XI, XII involves the anesthetist and presents challenges for airway management.

Monitoring of $\mathrm{CN} \mathrm{X}$ in children may require adhesive laryngeal electrodes when specialized pediatric EMG tracheal tubes are unavailable. Using these electrodes require pre-determination of optimum tube size and depth. Wrapping these electrodes around tracheal tubes increase external diameter (Fig. 2) and stiffness; prudent ETT size selection is necessary to prevent airway trauma. In addition, when these electrodes are applied to smaller tube sizes to accommodate smaller patients, the bulk of the electrode becomes more apparent relative to the ETT (Fig. 3), further downsizing of tracheal tube should be kept in view. Following our experience from patient 1 , a slightly smaller tube was selected for patient 2 , the microcuff advantageous because cuff inflation would 


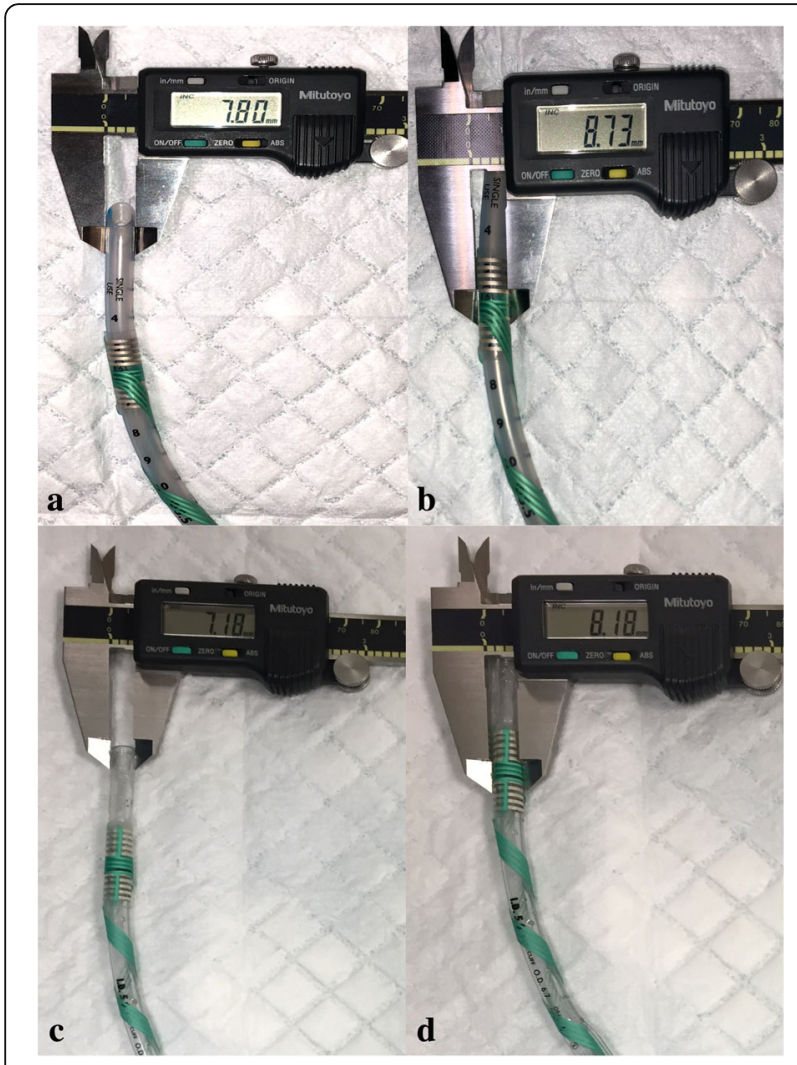

Fig. 2 Increased external diameter due to electrode. A and $b$ is demonstrated on a \#5.5 uncuffed ETT, $c$ and $d$ is demonstrated on a \#5.0 micrcuff ETT

ensure good seal despite downsizing should a leak arise, and minimize the need for tube change.

A new procedure presents a steep learning curve, not only in technicalities but also in workflow process. Our MRI location is separate and remote

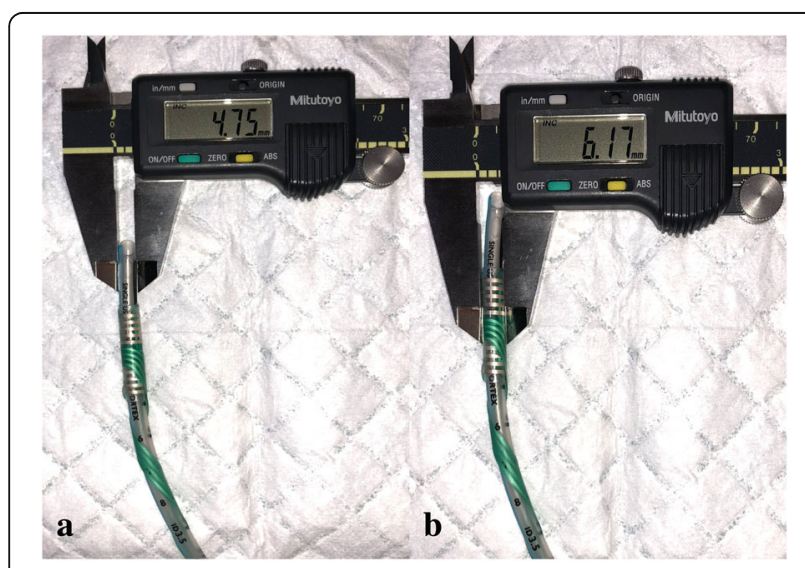

Fig. 3 Same electrode demonstrated on a \#3.5 ETT. There is a larger increase in external diameter due to overlapping of the wrappings $(\sim 1.4 \mathrm{~mm})$, compared to its application on a larger ETT (c.f. Fig. 2, where increase in external diameter is $\sim 1 \mathrm{~mm}$ ) from the operating theatre. Definitive airway and electrode placement was conducted post MRI, in the operating theatre, as the electrodes are not MRI compatible. Patient 1 presented with mild rhinorrhea, but appeared otherwise well. We decided to proceed with the case as international expertise was engaged to advise on this first attempt in Singapore. Hence, patient 1 was intubated at MRI for transport to operating theatre, to eliminate en route laryngospasm. For patient 2, a laryngeal mask was chosen first, as a microcuff ETT is a limited and more expensive resource. To date, the workflow has evolved such that the preoperative MRI is conducted on another occasion, to minimize risks associated with transport.

Bite blocks on either side of the tracheal tube prevent bite occlusion and centralize the tube, maintaining optimal contact between electrode and bilateral vocal cords. Positioning the patient in a simulated surgical position first enables best estimation of electrode position on the tracheal tube for $\mathrm{CN} \mathrm{X} \mathrm{moni-}$ toring during surgery. Video-laryngoscope aids in optimizing placement of the laryngeal electrode, and in placement of IX pin electrodes in the soft palate. In both cases the ETT had displaced slightly in a cranial fashion by the end of the procedure, and we recommend wrapping the electrode slightly lower with this in mind.

Tracheal intubation was facilitated using remifentanil. Vocal cord topicalization and muscle relaxants were omitted to avoid interference with $\mathrm{CN} \mathrm{X}$ and MEP monitoring respectively. Where evidence regarding the impact of local anaesthetic topicalization on neuromonitoring integrity appears to be conflicting [5], we feel that this is a potential simple confounder, which can be simply eliminated from the complex equation of troubleshooting loss of signal [6].

Intra-oral CN IX and CN XII pins pose a foreign body aspiration risk. A practice of preoperative huddle and verification process tracks the number of intraoral implants placed. A sign out process at procedure end confirms that all electrodes are removed.

Both children experienced prolonged postoperative nausea and vomiting despite anti-emetics, a larger cohort study is needed to confirm this observation.

In summary, neurophysiology monitoring of cranial nerve IX, X, XII in the ABI procedure requires intraoral placement of electrodes. Care should be exercised during placement and removal. Vagus nerve monitoring in children requires attention to tube preparation. Consideration should be given to avoidance of airway topicalization.

(1) Intraoperative neuromuscular monitoring for auditory brainstem implant includes brainstem 
auditory evoked response, brainstem mapping of CN IX, X, XI, XII and their motor nuclei, and corticobulbar tract motor-evoked potential monitoring.

(2) Monitoring of cranial nerve $\mathrm{X}$ in children requires placement of laryngeal electrodes around tracheal tube, necessitating pre-determination of optimal tube size and depth - Considerations include downsizing and potential displacement.

(3) Avoidance of topical anesthesia to larynx facilitates intraoperative neuromonitoring of motor X nerve.

\section{Abbreviations}

ABI: Auditory Brainstem Implant; CN: Cranial Nerve; EMG: Electromyogram; ETT: Endotracheal tube; LA: Local anesthestic; MEP: Motor Evoked Potential; MRI: Magnetic Resonance Imaging

\section{Acknowledgements}

We would like to thank the family and patients depicted here for allowing us to share their pioneering story.

\section{Funding}

None.

\section{Availability of data and materials}

All relevant data has been included. Further info can be requested from the author.

\section{Authors' contributions}

Author $\mathrm{CK}, \mathrm{NAH}$ and $\mathrm{HIH}$ was involved in conduct of anesthesia for patient 1. Author CK, AT and TT was involved in conduct of anesthesia for patient 2. Author CK and NAH was involved in literature search regarding the topic. Author $\mathrm{CK}$ wrote the contents of this article. Author $\mathrm{HIH}$ is the main editor. All authors have contributed in editing, and to the experiences dictated in this article. All authors read and approved the final manuscript.

\section{Ethics approval and consent to participate}

This was discussed with IRB at KK Women's and Children's Hospital. Formal ethics approval not required; institutional media consent to be obtained. The parents of both patients signed this.

\section{Consent for publication}

Written consent was obtained from the parents of both patients. Consent was obtained for photography/videography/audiotape/oral and/or written medical information, for the purpose of research publications.

\section{Competing interests}

None.

\section{Publisher's Note}

Springer Nature remains neutral with regard to jurisdictional claims in published maps and institutional affiliations.

Received: 10 June 2018 Accepted: 24 October 2018

Published online: 07 November 2018

\section{References}

1. Puram SV, Tward AD, Jung DH, Dilger AE, Herrmann BS, Duhaime A-C, et al. Auditory brainstem implantation in a 16-month-old boy with Cochlear hypoplasia. Otol Neurotol. 2015;36(4):618-24.

2. Shapiro WH. 20Q: Auditory brainstem implants - continued advancements for both adults and children [internet]. 2015. Available from: http://www.audiologyonline.com/articles/20q-auditory-brainstemimplants-continued-15810

3. Absalom A, Kenny G. 'Paedfusor' pharmacokinetic data set. Br J Anaesth 2005 Jul;:95(1):110
4. Francis L, Mohamed M, Patino M, McAuliffe J. Intraoperative neuromonitoring in pediatric surgery. Int Anesthesiol Clin. 2012;50(4):130-43.

5. Pachuski J, Vaida S, Donahue K, Roberts J, Kunselman A, Oberman B, et al. Effect of laryngotracheal topical anesthesia on recurrent laryngeal nerve monitoring during thyroid surgery. J Clin Anesth. 2016;29:10-3.

6. Macias AA, Eappen S, Malikin I, Goldfarb J, Kujawa S, Konowitz PM, et al. Successful intraoperative electrophysiologic monitoring of the recurrent laryngeal nerve, a multidisciplinary approach: the Massachusetts eye and ear infirmary monitoring collaborative protocol with experience in over 3000 cases. Head Neck. 2016;38(10):1487-94.

\section{Ready to submit your research? Choose BMC and benefit from:}

- fast, convenient online submission

- thorough peer review by experienced researchers in your field

- rapid publication on acceptance

- support for research data, including large and complex data types

- gold Open Access which fosters wider collaboration and increased citations

- maximum visibility for your research: over $100 \mathrm{M}$ website views per year

At BMC, research is always in progress.

Learn more biomedcentral.com/submissions 